\title{
What are the Most Effective Factors in Determining Future Exacerbations, Morbidity Weight and Mortality In Patients Hospitalized with COPD Attack? A Prospective Study
}

\author{
Çă̆la Koç ${ }^{1}$ and Füsun Şahin ${ }^{2}$ \\ ${ }^{1}$ Ministry of Health, Erbaa State Hospital, Tokat/Turkey. \\ ${ }^{2}$ University of Health Sciences, Yedikule Chest Diseases and Thoracic Surgery Training and \\ Research Hospital
}

July 22, 2021

\begin{abstract}
INTRODUCTION: The aim of this study was to investigate the important factors affecting the COPD prognosis. MATERIAL AND METHODS: We included 160 hospitalized patients with COPD exacerbation in the study. Hemoglobin-HB, hematocritHCT, leukocyte, red cell distribution width- RDW, mean platelet volume, platelet distribution width, plateletcrit, platelet, neutrophil / lymphocyte ratio, platelet / lymphocyte ratio, eosinophil, uric acid, albumin, CRP, procalcitonin, arterial blood gases (PO2, PCO2) pulmonary function test (FEV1, FVC), echocardiography (ejection fraction-EF) GOLD stage, MMRC and BORG scales, Charlson comorbidity index, body mass index-BMI, length of hospital stay were examined on the first day of hospitalization. Admission to the hospital with a new attack, hospitalization in the intensive care unit-ICU, and mortality during the 6 months after discharge were evaluated. RESULTS: High CRP and procalcitonin values were observed in the group with long hospital stay. In mortality group, HB, HCT, BMI and PO2 values were significantly lower than the group without mortality while age and GOLD stage were higher. The age, BORG and MMRC scores, number of exacerbations experienced in the previous 1 year, RDW, eosinophil count, PCO2 were significantly higher in the ICU group than without ICU. HCT, EF values were lower in the ICU group than without ICU. FEV1, FVC values were significantly lower in follow-up attack group than without attack; the duration of COPD and the number of experienced in the previous 1 year were high. CONCLUSION: It has been concluded that the scoring combining selected biomarkers and other factors will be stronger in determining the prognosis.
\end{abstract}

\section{Hosted file}

MAIN DOCUMENT.doc available at https://authorea.com/users/427121/articles/531376-what-arethe-most-effective-factors-in-determining-future-exacerbations-morbidity-weight-andmortality-in-patients-hospitalized-w\%C4\%B1th-copd-attack-a-prospective-study

\section{Hosted file}

Table File.doc available at https://authorea.com/users/427121/articles/531376-what-arethe-most-effective-factors-in-determining-future-exacerbations-morbidity-weight-andmortality-in-patients-hospitalized-w\%C4\%B1th-copd-attack-a-prospective-study 